\title{
ESTRUTURA E PRODUTIVIDADE DE CAPIM-TANZÂNIA SUBMETIDO A DIFERENTES FREQUÊNCIAS DE DESFOLHAÇÃO
}

\section{STRUCTURE AND PRODUCTIVITY OF TANZANIA GRASS SUBJECTED TO DIFFERENT DEFOLIATION FREQUENCIES}

\author{
Vitor Hugo Maués Macedo ${ }^{1 *}$ \\ Antônio Marcos Quadros Cunha ${ }^{1}$ \\ Ebson Pereira Cândido ${ }^{1}$ \\ Felipe Nogueira Domingues ${ }^{1}$ \\ Deyvid de Menezes Melo ${ }^{2}$ \\ Aníbal Coutinho do Rêgo ${ }^{2}$ \\ ${ }^{1}$ Universidade Federal do Pará, Belém, PA, Brasil. \\ ${ }^{2}$ Universidade Federal Rural da Amazônia, Belém PA, Brasil. \\ "Autor para correspondência - vitorhugo.macedo11@gmail.com
}

\section{Resumo}

Objetivou-se com este trabalho avaliar o efeito de diferentes frequências de desfolhação em períodos fixos sob as características estruturais e produtivas do dossel de capim-Tanzânia (Panicum maximum Jacq) em condições climáticas Am no ano de 2014. O delineamento experimental foi em blocos casualizados com seis tratamentos correspondentes a seis frequências de desfolhação (14; 21; 28; 35; 42 e 49 dias) e cinco repetições e os dados foram submetidos a análise de regressão. A interceptação luminosa (IL) aumentou $(\mathrm{P}<0,05)$ de maneira assintótica com o aumento dos períodos de descanso, no qual a máxima interceptação de luz foi de $98 \%$ e ocorreu aos 42 dias de rebrotação. $\mathrm{O}$ índice de área foliar (IAF) e o acúmulo de matéria seca, aumentaram $(\mathrm{P}<0,05)$ linearmente variando de 3,6 a 7,1 e de 880,3 a 4051,7 kg.ha ${ }^{-1}$ de matéria seca de forragem, nas frequências de 14 a 49 dias, respectivamente. A altura variou de 44 a $119 \mathrm{~cm}$ nas frequências de 14 a 49 dias, respectivamente. A frequência de desfolhação que representa uma IL de 95\% está relacionada ao período de descanso de 29 dias, em que o dossel de capim-Tanzânia apresentou altura em torno de $63 \mathrm{~cm}$, IAF crítico de 5,1 e acúmulo de matéria seca de forragem de $2.160 \mathrm{~kg} \cdot \mathrm{ha}^{-1}$.

Palavras-chave: Área foliar; dossel; interceptação luminosa; massa seca; Panicum maximum.

\begin{abstract}
The objective of the present study was to evaluate the effect of different frequencies of defoliation at fixed periods on the structural and productive characteristics of Tanzania grass (Panicum maximum) under Am climate conditions in 2014. The experimental design was in complete randomized blocks with six treatments corresponding to six frequencies of defoliation $(14,21,28$, 35,42 , and 49 days) and five repetitions. The data was submitted to regression analysis. The light interception $(\mathrm{LI})$ increased $(\mathrm{P}<0.05)$ in an asymptotic way with increasing rest periods. The
\end{abstract}


maximum light interception was $98 \%$ and occurred at 42 days of regrowth. The leaf area index (LAI) and the dry matter accumulation increased ( $\mathrm{P}<0.05)$ linearly varying from 3.6 to 7.1 and from 880.3 to $4051.7 \mathrm{~kg} . \mathrm{ha}^{-1}$ of forage dry matter in the frequencies $14-49$ days, respectively. The height ranged 44-119 $\mathrm{cm}$ at frequencies 14-49 days, respectively. The frequency of defoliation at 95\% LI is related to the rest period of 29 days, where the Tanzania grass canopy presented around $63 \mathrm{~cm}$ height, critical LAI of 5.1, and forage dry matter accumulation of 2,160 $\mathrm{kg} \mathrm{ha}^{-1}$.

Keywords: canopy; dry matter; leaf area; light interception; Panicum maximum.

Recebido em: 09 dezembro de 2015

Aceito em: 29 novembro de 2016

\section{Introdução}

Na Amazônia Legal, houve um acréscimo de 12,67\% no rebanho bovino de 2004 a 2013, aumentando de 71,6 milhões de cabeças para 80,7 milhões, respectivamente ${ }^{(1)}$. Em contrapartida, na mesma região houve um decréscimo de 78,8\% na abertura de novas áreas durante o mesmo período, passando de $27.772 \mathrm{~km}^{2}$ para $5.891 \mathrm{~km}^{2}$ de área desmatada ${ }^{(2)}$. Fica claro o desafio da busca pelo aumento da produção, em decorrência da maior demanda por alimentos, em áreas cada vez menores.

O clima do tipo Am pertence ao grupo climático A da classificação de Köppen, que se caracteriza por ser um clima tropical chuvoso com temperatura média de todos os meses maior que $18{ }^{\circ} \mathrm{C}$. Além de ser uma forma intermediária entre as classes Af e Aw, a classe Am apresenta uma breve estação seca no ano e chuvas intensas no restante do período ${ }^{(3)}$.

O aumento da produtividade em sistemas de produção animal a pasto exige cada vez mais o uso de plantas forrageiras de maior potencial produtivo, proporcionando maior taxa de lotação. Gramíneas da espécie Panicum maximum destacam-se pela alta produtividade e alto valor nutritivo ${ }^{(4-5)}$. Silva e Nascimento $\mathrm{Jr}^{(6)}$ afirmam que o manejo do pastejo é um fator importante que deve ser considerado, pautado no conhecimento relativo à ecofisiologia das plantas forrageiras, assumindo papel de destaque e constituindo premissa básica para a idealização e recomendação de práticas de manejo sustentáveis que permitam aumentar a produção e a produtividade dos sistemas de produção.

De acordo com Lara et al. ${ }^{(7)}$, apesar da crescente produção de pesquisas que utilizam a interceptação de luz do dossel como premissa básica de colheita da forragem, para fins de modelagem e/ou potencial de crescimento, os métodos tradicionais de colheita baseados em períodos fixos de rebrotação são valiosos na construção de bancos de dados em que o efeito do ambiente é o mesmo sobre o objeto de estudo, atribuindo-se as variações nos resultados aos tratamentos aplicados.

O capim-Tanzânia tem sido sistematicamente testado e recomendado para a utilização na região do Brasil Central $^{(8-10)}$. No entanto, há poucos estudos disponíveis sobre o potencial de produção e adaptabilidade deste cultivar nas condições climáticas classificadas como Am. Além disso, não há indicações precisas quanto à forma de gerir esta planta a fim de se compreender e facilitar o planejamento e gestão para se garantir o manejo adequado. Objetivou-se com o este trabalho avaliar o efeito de diferentes frequências de desfolhação, em períodos fixos de descanso, na estrutura e 
produção de forragem do capim-Tanzânia por meio do acúmulo de massa seca, índice de área foliar (IAF), interceptação luminosa (IL) e altura do dossel, durante o período de transição do período chuvoso para o período seco nas condições climáticas Am.

\section{Material e Métodos}

O estudo foi conduzido no campo experimental da Fazenda Escola de Igarapé-Açu (FEIGA) da Universidade Federal Rural da Amazônia (UFRA), no município de Igarapé-Açu - PA, a 0107'21" S e $47^{\circ} 36^{\prime} 27^{\prime \prime}$ W, no ano de 2014. O campo localiza-se no bioma amazônico, com temperatura média anual em torno de $28^{\circ} \mathrm{C}$. As chuvas não se distribuem homogeneamente durante o ano. No geral, os totais mensais mais altos ocorrem entre janeiro e maio, com precipitação em torno de 350 mm ao mês, e os menos elevados, entre setembro e dezembro, com precipitações inferiores a 80 $\mathrm{mm}$ ao mês. O período experimental de 92 dias (com inicio no dia 24/05/2014, com o corte de nivelamento do dossel forrageiro de todas as parcelas, e final no dia 06/09/2014) ocorreu na fase de transição do período chuvoso para o período seco (Figura 1).

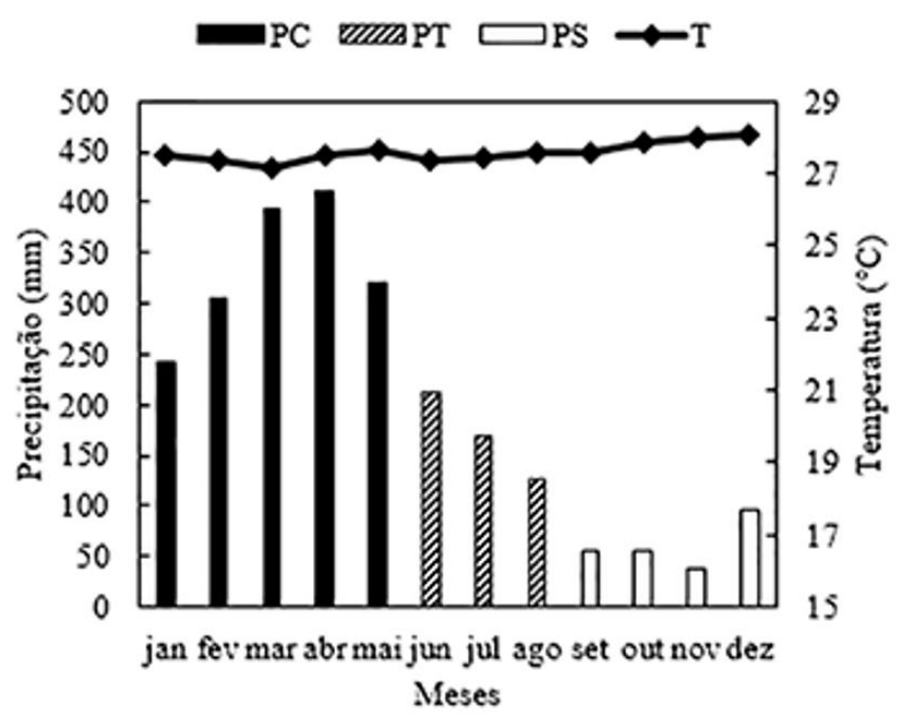

Figura 1. Média mensal da precipitação pluviométrica $(\mathrm{mm})$ e da temperatura média $\left({ }^{\circ} \mathrm{C}\right)$ do municipio de Igarapé-Açu - PA. Periodos: 2003 - 2013. PC- periodo chuvoso; PT- periodo de transição; PS - periodo seco; $T$ - temperatura média.

Fonte: Dados da estação meteorológica da EMBRAPA de Igarapé-Açu.

As condições gerais de clima quente e úmido enquadram a região nos tipos climáticos Am, da classificação de Köppen, e B2rAa', da classificação de Thornthwaite. Ambos significam clima tropical sem ocorrência de inverno estacional. O solo do local é classificado como Latossolo amarelo, de textura franco-arenosa e de baixa fertilidade (Tabela 1). 
Tabela 1. Resultado de análise quimica do solo $(0-20 \mathrm{~cm})$ da ärea experimental, Igarapé-Açu, PA

\begin{tabular}{cccccccccrr}
\hline \multicolumn{2}{c}{ pH } & Carb. Org. & Mat. Org. & P & N & K & Ca & Mg & Al & $\mathrm{H}+\mathrm{Al}$ \\
\hline $\mathrm{H}_{2} \mathrm{O}$ & $\mathrm{KCl}$ & $\mathrm{g} \mathrm{kg}^{-1}$ & $\mathrm{~g} \mathrm{~kg}^{-1}$ & $\mathrm{mg} \mathrm{dm}^{-3}$ & $\mathrm{~g} \mathrm{~kg}^{-1}$ & \multicolumn{5}{c}{$\mathrm{cmol}_{2} \mathrm{dm}^{-3}$} \\
\hline 4,95 & 4,16 & 17,74 & 30,59 & 1,44 & & 0,03 & 0,74 & 0,28 & 0,72 & 5,08 \\
\hline
\end{tabular}

$\mathrm{pH}=$ potencial hidrogeniônico; Caro. Org. = carbono orgânico; Mat. Org. = matéria orgânica; $\mathrm{P}=$ fósforo; $\mathrm{N}=$ nitrogênio; $\mathrm{K}=$ potássio; $\mathrm{Ca}=$ cálcio; $\mathrm{Mg}$ = magnésio; $\mathrm{Al}=$ aluminio; $\mathrm{H}+\mathrm{Al}=$ hidrogênio mais aluminio.

Para o capim-Tanzânia foi necessário fazer correção do solo com calcário dolomítico na aplicação de uma dose equivalente à 2,9 ton.ha ${ }^{-1}$. O solo foi preparado com uso de grade aradora, seguido de destorroamento por meio de grade niveladora. A semeadura ocorreu no dia 06/03/2014, utilizandose sementes adquiridas comercialmente, junto com adubação fosfatada (super-fosfato-simples $18 \%$ de $\mathrm{P}_{2} \mathrm{O}_{5}$ ) a uma dose equivalente a $80 \mathrm{~kg}$ de $\mathrm{P}_{2} \mathrm{O}_{5}$ por hectare, aplicados a lanço. Durante o período experimental, para a manutenção de nutrientes no sistema, realizou-se adubação nitrogenada na forma de ureia equivalente a $200 \mathrm{~kg} \cdot \mathrm{ha}^{-1} \cdot \mathrm{ano}^{-1}$ de $\mathrm{N}$ e adubação potássica na forma de cloreto de potássio equivalente a $80 \mathrm{~kg} \cdot \mathrm{ha}^{-1} \cdot \mathrm{ano}^{-1}$ de $\mathrm{K}_{2} \mathrm{O}$.

Os tratamentos representaram seis frequências de desfolhação correspondendo a seis períodos fixos de descanso: 14; 21; 28; 35; 42 e 49 dias. O delineamento experimental foi em blocos casualizados com cinco repetições, totalizando 30 unidades experimentais dispostas em parcelas, cada uma medindo $12 \mathrm{~m}^{2}$ ( $\left.3 \mathrm{~m} \times 4 \mathrm{~m}\right)$, separadas por corredores de $1 \mathrm{~m}$ de largura. Após o plantio, o dossel forrageiro nas parcelas permaneceu em crescimento livre, até que no dia 24/05/2014 o dossel de todas as parcelas foi nivelado dando início ao experimento. A partir desse momento, cada tratamento recebeu o corte de acordo com o período fixo de descanso, a uma altura de $20 \mathrm{~cm}$ do solo, gerando diferentes ciclos de desfolhação em cada tratamento, detalhados na Tabela 2.

Tabela 2. Cronograma de cortes do dossel forrageiro de cada tratamento durante o periodo experimental (24/05/2014 a 6/9/2014), Igarapé-Açu, PA

\begin{tabular}{ccccccccc}
\hline Tratamentos & \multicolumn{8}{c}{ Ciclos de desfolhação } \\
\hline & Nivelamento & 1 & 2 & 3 & 4 & 5 & 6 & 7 \\
\hline 14 dias & $24 / 5$ & $7 / 6$ & $21 / 6$ & $5 / 7$ & $19 / 7$ & $2 / 8$ & $16 / 8$ & $30 / 8$ \\
21 dias & $24 / 5$ & $14 / 6$ & $5 / 7$ & $26 / 7$ & $16 / 8$ & $6 / 9$ & & \\
28 dias & $24 / 5$ & $21 / 6$ & $19 / 7$ & $16 / 8$ & & & & \\
35 dias & $24 / 5$ & $28 / 6$ & $2 / 8$ & $6 / 9$ & & & & \\
42 dias & $24 / 5$ & $5 / 7$ & $16 / 8$ & & & & & \\
49 dias & $24 / 5$ & $12 / 7$ & $30 / 8$ & & & & & \\
\hline
\end{tabular}

Ao final de cada período de descanso, para as características estruturais pré-desfolhação, foram feitas as seguintes avaliações nas parcelas: IAF e IL do dossel, estimados utilizando-se o aparelho analisador de dossel - AccuPAR Linear PAR/LAI ceptometer (LP-80, Decagon Devices, Pullman, WA, USA), as medições foram realizadas em 5 pontos aleatórios, em cada uma das parcelas 
experimentais; e altura do dossel, estimada medindo-se a altura em 5 pontos aleatórios por parcela experimental, utilizando-se uma régua graduada em centímetros. A média dos pontos representou a medida de IAF, IL e altura do dossel em cada parcela no momento do corte. O valor para cada tratamento foi calculado dividindo-se a soma do valor de cada variável antes do corte pelo número de ciclos existentes em cada tratamento.

No momento de cada corte foram feitas amostragens para quantificação do acúmulo de biomassa, retirando-se, de cada parcela, uma amostra de forragem contida no interior de uma moldura metálica retangular medindo $0,5 \times 1,0 \mathrm{~m}$, a $20 \mathrm{~cm}$ do nível do solo. $\mathrm{O}$ corte foi realizado com o auxílio de um aparador de cerca viva, em pontos da parcela onde a condição de vegetação do dossel era representativa da média. Após a coleta da amostra, toda a vegetação dentro da parcela foi nivelada a $20 \mathrm{~cm}$ do solo, estimulando-se a rebrotação para o corte posterior. As amostras frescas foram acondicionadas em sacos plásticos, identificadas e levadas ao laboratório para a pesagem total da forragem. Em seguida, retirou-se um subamostra de aproximadamente $600 \mathrm{~g}$ que foi colocada em saco de papel, novamente pesada e levada à estufa de ventilação forçada à $55{ }^{\circ} \mathrm{C}$ para secagem até peso constante. $\mathrm{O}$ acúmulo médio de massa seca de forragem por tratamento foi calculado dividindo-se a soma do valor de acúmulo de cada corte pelo número de ciclos existente em cada tratamento.

Os dados de acúmulo médio de massa seca, IL, IAF e altura foram analisados por meio de análise de regressão. Ajustaram-se os modelos de regressão que foram escolhidos com base na significância dos coeficientes de regressão ao nível de $5 \%$ de probabilidade. Como ferramenta de auxílio às análises estatísticas, foi utilizado o programa computacional Sisvar versão $5.3^{(11)}$.

\section{Resultados e Discussão}

A IL do dossel foi afetada pela frequência de desfolhação $(\mathrm{P}<0,05)$ e aumentou de maneira assintótica em função das frequências de desfolhação (Figura 2). A representação gráfica da análise de regressão mostra um crescimento inicial acentuado que se estabilizou depois. A máxima interceptação de luz foi de $98 \%$ e ocorreu aos 42 dias de rebrotação.

Mello e Pedreira ${ }^{(12)}$, ao estudarem o capim-Tanzânia, verificaram tendências semelhantes, indicando um aumento da IL com a altura do dossel até certo ponto, a partir do qual esse aumento de altura não afeta a IL, que se mantem praticamente constante, apresentando um comportamento que tende a um crescimento exponencial. Isso está intimamente relacionado com o hábito de crescimento ereto dessa espécie, de arquitetura vertical que, consequentemente, por mais que aumente a altura, quase sempre permitirá a passagem de radiação para regiões abaixo do dossel.

A IL de $95 \%$ é tida como o momento a partir do qual as plantas modificam a dinâmica de acúmulo de matéria seca, reduzindo o acúmulo de lâminas foliares e aumentando rapidamente o acúmulo de colmos e de material morto. Esse valor remete ao momento ideal para se interromper o processo de rebrotação das plantas forrageiras ${ }^{(6)}$. 


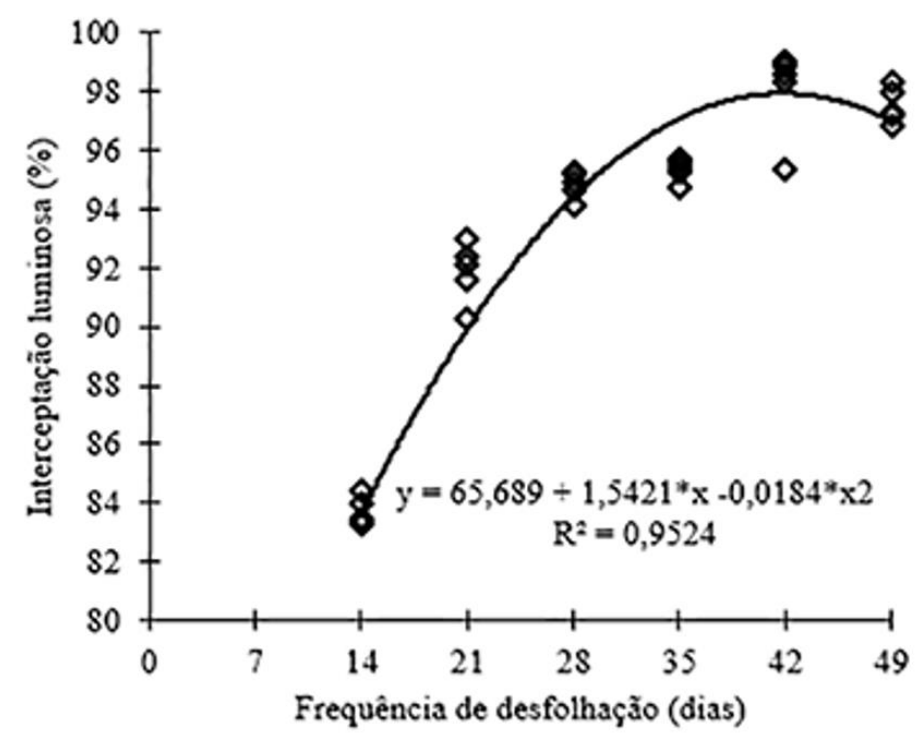

Figura 2. Interceptação luminosa do dossel de capim-Tanzânia sob seis frequências de desfolhação.

A equação de regressão permite estimar um valor esperado para uma IL de $95 \%$ que, nessas condições experimentais (clima Am), significa uma idade de rebrotação de 29 dias, utilizando-se um resíduo com $20 \mathrm{~cm}$ de altura no período de transição do chuvoso para o seco. Barbosa et al. ${ }^{(8)}$ realizaram um experimento com capim-Tanzânia sob condições de clima tipo Aw, no período que abrange a estação com maior disponibilidade de fatores de crescimento do capim (luz, temperatura, água) - primavera e verão. Os autores observaram que a IL de 95\% pelo dossel de capim-Tanzânia sob lotação intermitente ocorreu em intervalos médios de 32 dias e, diferente do presente experimento, o intervalo de 29 dias promoveu uma IL de $90 \%$.

Cutrim Junior et al. ${ }^{(13)}$ notaram períodos de descanso em torno de 26 dias em sistema de lotação intermitente em pastos de capim-Tanzânia com ovinos no Ceará. As condições de pasto irrigado, adubação nitrogenada equivalente a $600 \mathrm{~kg} \mathrm{ha}^{-1} \mathrm{ano}^{-1}$ de $\mathrm{N}$ e presença dos ovinos, o que aumenta a entrada de nutriente via resíduos animais no sistema, podem ter influenciado para um menor período de descanso do capim em relação ao presente experimento.

Houve crescimento linear $(\mathrm{P}<0,05)$ do índice de área foliar (IAF) médio, ao longo do avanço das idades de rebrota, variando de 3,6 a 7, nas frequências de 14 a 49 dias, respectivamente (Figura 3). Comportamento semelhante foi observado por Mello e Pedreira ${ }^{(12)}$ ao longo do ano sob clima Cwa. Esses autores afirmam que esse tipo de resposta está de acordo com a literatura, que reporta aumentos lineares do IAF médio à medida que se avança o período de rebrota em função de taxas crescentes de fotossíntese de dossel. 


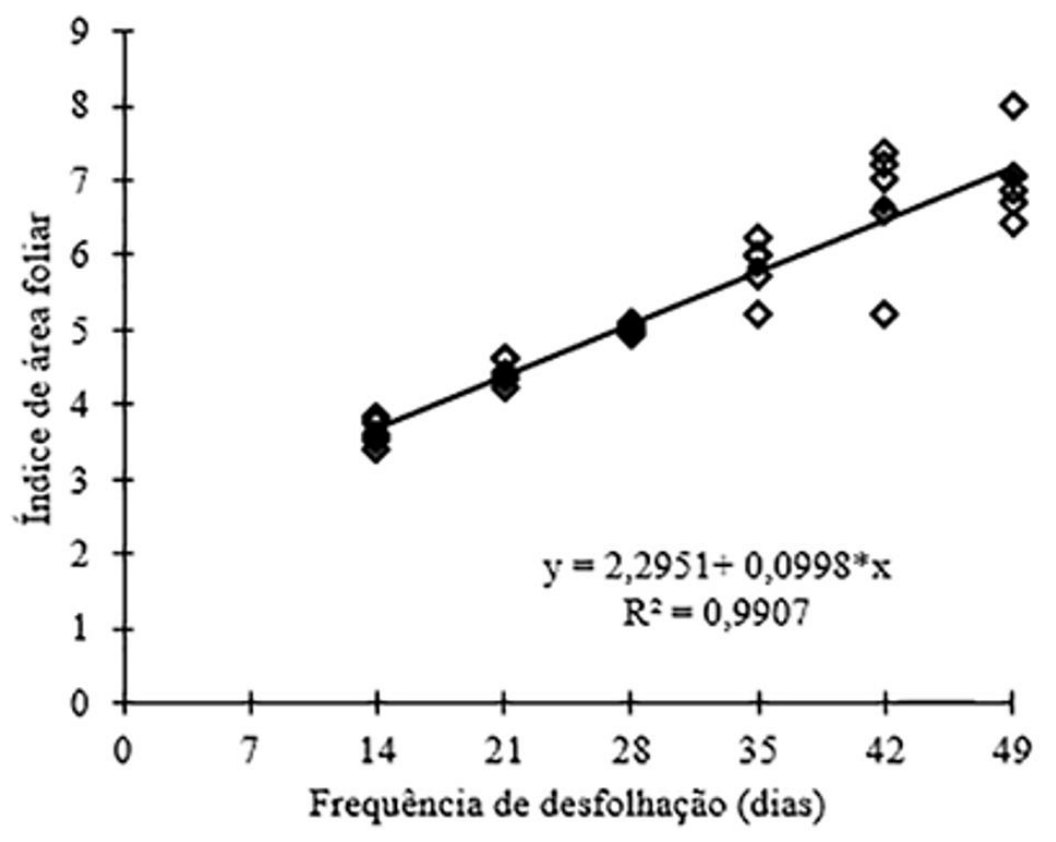

Figura 3. Índice de área foliar do capim-Tanzânia sob seis frequências de desfolhação.

Neste estudo, a IL de $95 \%$ foi alcançada próximo do $29^{\circ}$ dia de rebrotação, que corresponde a um IAF crítico em torno de 5,1. O valor ideal de IAF encontra-se entre 3 e 5 . Acima desse valor atingese o IAF crítico, ou seja, a partir desse ponto, se o IAF continuar a crescer, as folhas inferiores passam a ser sombreadas e se tornam menos eficientes fotossinteticamente. As plantas modificam a dinâmica de acúmulo de matéria seca, reduzindo a formação de lâminas foliares e aumentando rapidamente o acúmulo de colmos e material morto, provocado pelo aumento das perdas respiratórias, em consequência do sombreamento excessivo, que resulta em balanço negativo de carbono. Vale enfatizar que a produção de colmos compromete a relação folha/colmo da forragem e, portanto, o valor nutritivo e o desempenho dos ruminantes em pastejo ${ }^{(14)}$.

Mello e Pedreira ${ }^{(12)}$ verificaram que a uma IL próxima de $95 \%$ correspondeu um IAF médio em torno de 3,5 aos 22 dias de rebrota. Os mesmos autores relatam ainda que, de maneira geral em pastagens, valores de IAF crítico situam-se normalmente entre 3 e 5.

A altura de pré-desfolhação é representada graficamente por uma função quadrática, indicando aumento da altura com o aumento do intervalo entre desfolhações $(\mathrm{P}<0,05)$, que variou de 44 a 119 $\mathrm{cm}$ de altura (Figura 4). A redução da frequência de desfolhação com o aumento do intervalo de corte resultou em maior altura pré-desfolhação, já que plantas de crescimento ereto tendem a alongar o colmo para colocar as novas folhas no topo do dossel.

No presente estudo, a IL de $95 \%$ correspondeu a uma altura em torno de $63 \mathrm{~cm}$. Resultado superior ao observado por Mello e Pedreira ${ }^{(12)}$ que, em valores de IL próximos de $95 \%$, observaram valores de altura média do dossel em torno de $55 \mathrm{~cm}$. Sob essa IL, a altura ideal de desfolhação do capimTanzânia, em alguns estudos, estaria entre os valores de 70 a $75 \mathrm{~cm}^{(8,10)}$. Sob intervalos de desfolhação superiores aos deste experimento, Castro et al. ${ }^{(15)}$ observaram aumento da altura com o aumento da idade de corte de capim-Tanzânia de 42 dias até 84 dias, porém sem diferença significativa entre as idades de 84 a 126 dias. 


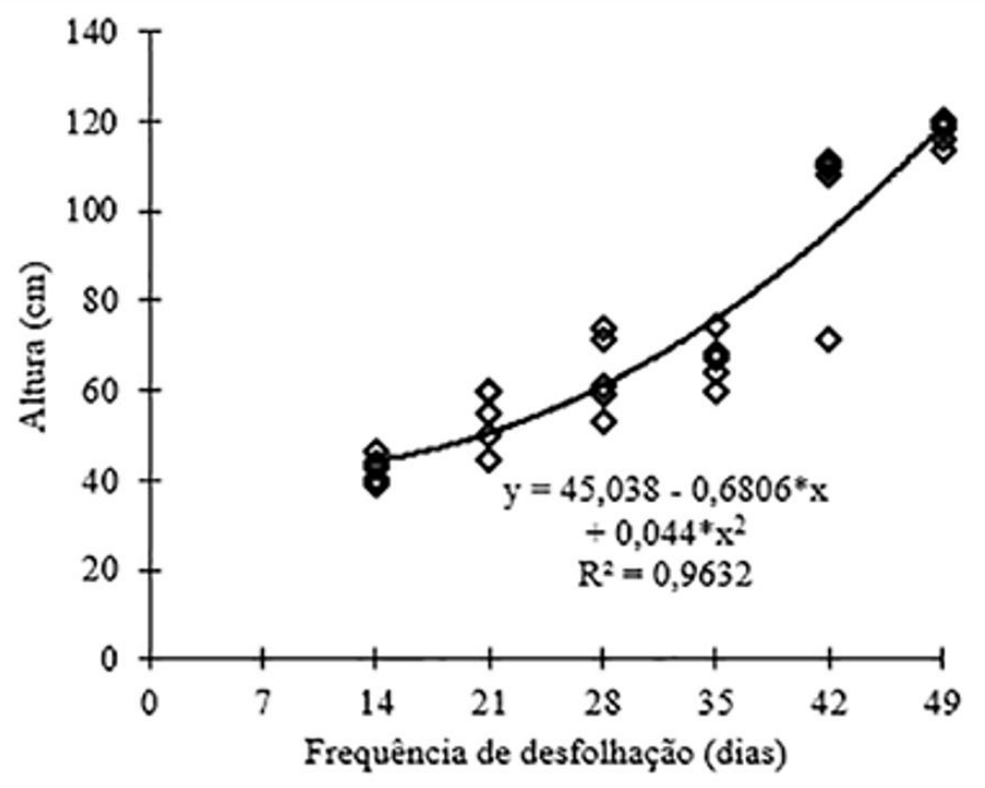

Figura 4. Altura de prè-desfolhação média do capim-Tanzània sob seis frequências de desfolhação.

A altura do pasto é uma característica importante para o manejo e tem grande influência sobre consumo animal em pastejo, o que pode garantir rendimentos satisfatórios de forragem e massa de folha associados a um tempo de pastejo mais curto e maior consumo de forragem ${ }^{(16)}$.

$\mathrm{O}$ acúmulo médio de massa seca de forragem aumentou $(\mathrm{P}<0,05)$ linearmente com o aumento do intervalo de corte e com a redução da frequência de desfolhação, variando de 880,3 a $4.051,7$ kg.ha-1 de massa seca de forragem, nas frequências de 14 a 49 dias, respectivamente (Figura 5). Esse comportamento assemelha-se ao encontrado no trabalho de Santos et al. ${ }^{(17)}$, no qual a massa de forragem tanto do cultivar Tanzânia quanto do cultivar Mombaça aumentou com o intervalo de desfolhação.

Embora o alongamento de colmos favoreça o aumento da produção de massa seca, ele pode influenciar negativamente a eficiência de pastejo e o valor nutritivo da forragem produzida, além de aumentar o intervalo de aparecimento de folhas, ou seja, o filocrono. De acordo com Santos et al. ${ }^{(18)}$, um dos grandes problemas no manejo do capim-Tanzânia é o aumento da participação dos colmos com a chegada da época de florescimento. Esse problema pode ser estendido a outras espécies de clima tropical, pois, da mesma forma, ocorre o processo de alongamento de colmos na época de florescimento, variando apenas a altura de ocorrência.

No $29^{\circ}$ dia, quando a IL atingiu valores próximos de $95 \%$, o acúmulo médio de massa seca de forragem foi de aproximadamente $2.160 \mathrm{~kg} \cdot \mathrm{ha}^{-1}$, o que indica que após esse período passaria a acumular material senescente.

As características agrometeorológicas têm participação direta no acúmulo de matéria seca do capimTanzânia, principalmente nos parâmetros agrometeorológicos que levem em consideração o efeito térmico e hídrico conjuntamente, baseado na temperatura média, radiação solar e na disponibilidade hídrica ${ }^{(19)}$. Não houve diferença significativa $(\mathrm{P}>0,05)$ quanto à taxa de acúmulo de forragem entre os tratamentos, tendo média de 72,6 kg de massa seca (MS) ha ${ }^{-1} \cdot \mathrm{dia}^{-1}$. 


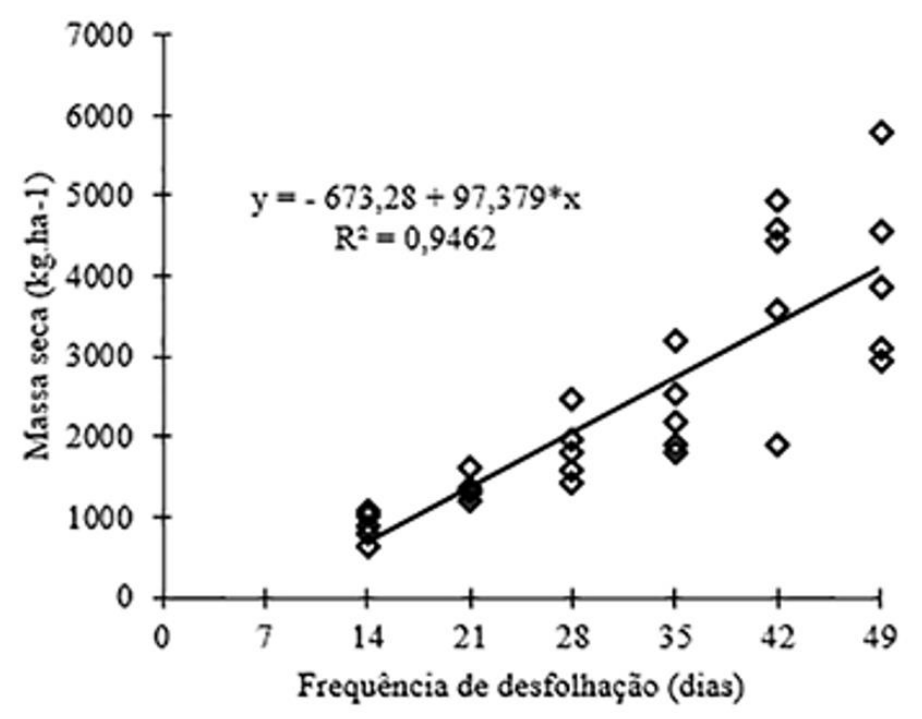

Figura 5. Acúmulo médio de massa seca forragem de capim-Tanzània sob diferentes frequências de desfolhação.

\section{Conclusões}

Nas condições climáticas Am, o período de descanso do capim-Tanzânia, para desfolhação mecânica, não deve ultrapassar os 29 dias de idade. Essa idade está relacionada a uma IL de 95\%, altura em torno de $63 \mathrm{~cm}$, IAF crítico de 5,1 e acúmulo de massa seca de forragem de $2.160 \mathrm{~kg}$.ha ${ }^{-1}$, durante o período de transição do período chuvoso para o período seco.

\section{Agradecimentos}

Os autores agradecem aos membros do Grupo de Estudos em Ruminantes e Forragicultura na Amazônia (GERFAM) da Universidade Federal Rural da Amazônia pela ajuda na condução do experimento.

\section{Referências}

1. IBGE. Banco de Dados Agregados - SIDRA: Pesquisa pecuária municipal [Internet]. 2014 [Acesso em: 2015 Out. 10]. Disponível em: http://www.ibge.gov.br/home/. Português.

2. INPE. Projeto PRODES: monitoramento da floresta amazônica brasileira por satélite. 2014 [Acesso em: 2015 Out. 10]. Disponível em: http://www.obt.inpe.br/prodes/index.php/. Português.

3. Sá Júnior A, Carvalho LG, Silva FF, et al. Application of the Köppen classification for climatic zoning in the state of Minas Gerais, Brazil. Theoretical and Applied Climatology. 2011;108(1):1-7. Disponível em: 


\section{http://dx.doi.org/10.1007/s00704-011-0507-8/.}

4. Rodrigues BHN, Magalhães JÁ, Lopes EA. Irrigação e adubação nitrogenada em três gramíneas forrageiras no Meio-Norte do Brasil. Revista Ciência Agronômica. 2005;36(3):274-278.

5. Fonseca DM, Martuscello JA. Plantas forrageiras. 1rd ver. Viçosa: Ed. UFV 2010. 537 p.

6. Silva SC, Nascimento Junior D. Avanços na pesquisa com plantas forrageiras tropicais em pastagens: características morfofisiológicas e manejo do pastejo. Revista Brasileira de Zootecnia. 2007;36(supl):121138.

7. Lara MAS, Pedreira CGS, Boote KJ, et al. Predicting Growth of: An Adaptation of the CROPGROPerennial Forage Model. Agronomy Journal. 2012;104(3):600-611.

8. Barbosa RA, Nascimento Junior D, Euclides VPB, et al. Capim-Tanzânia submetido a combinações entre intensidade e frequência de pastejo. Pesquisa Agropecuária Brasileira. 2007;42(3):329-340.

9. Velasquez PAT, Berchielli TT, Reis RA, et al. Composição química, fracionamento de carboidratos e proteínas e digestibilidade in vitro de forrageiras tropicais em diferentes idades de corte. Revista Brasileira de Zootecnia. 2010;39(6):1206-1213.

10. Zanine A, Nascimento Junior D, Santos MR, et al. Características estruturais e acúmulo de forragem em capim-Tanzânia sob pastejo rotativo. Revista Brasileira de Zootecnia. 2011;40(11):2364-2373.

11. Ferreira DF. Sisvar: a computer statistical analysis system. Versão 5.3 (Build 77). Lavras: UFLA; 2011.

12. Mello ACL, Pedreira CGS. Respostas morfológicas do capim-Tanzânia (Panicum maximum Jacq. cv. Tanzânia-1) irrigado à intensidade de desfolha sob lotação rotacionada. Revista Brasileira de Zootecnia. 2004;33(2):282-289.

13. Cutrim Junior JAA, Cândido MJD, Valente BSM, et al. Características estruturais do dossel de capimTanzânia submetido a três frequências de desfolhação e dois resíduos pós-pastejo. Revista Brasileira de Zootecnia. 2011;40(3):489-497.

14. Alexandrino E, Gomide JA, Gomide CAM. Crescimento e desenvolvimento do dossel de Panicum maximum cv. Mombaça. Revista Brasileira de Zootecnia. 2005;34(6):2164-2173.

15. Castro GHF, Rodriguez NM, Gonçalves LC, et al. Características produtivas, agronômicas e nutricionais do capim-Tanzânia em cinco diferentes idades ao corte. Arquivo Brasileiro de Medicina Veterinária e Zootecnia. 2010;62(3):654-666.

16. Ribeiro AM, Oliveira ME, Silva PC, et al. Canopy characteristics, animal behavior and forage intake by goats grazing on Tanzania-grass pasture with different heights. Acta Scientiarum. Animal Sciences. 2012;34(4):371-378.

17. Santos PM, Corsi M, Balsalobre AAM. Efeito da Frequência de Pastejo e da Época do Ano sobre a Produção e a Qualidade em Panicum maximum cv. Tanzânia e Mombaça. Revista Brasileira de Zootecnia. 1999;28(2):244-249.

18. Santos PM, Balsalobre AAM, Corsi M. Características morfogenéticas e taxa de acúmulo de forragem do capim-Mombaça submetido a três intervalos de pastejo. Revista Brasileira de Zootecnia. 2004;33(4):843851.

19. Pezzopane JRM, Santos PM, Mendonça FC, et al. Dry matter production of Tanzania grass as a function of agrometeorological variables. Pesquisa Agropecuária Brasileira. 2012;47(4):471-477. 